\title{
Differences in Immune Response to Porphyromonas gingivalis
}

\author{
${ }^{1}$ Laura M Tebloeva, ${ }^{2}$ Zalina E Revazova, ${ }^{3}$ Kate G Fabrikant, ${ }^{4}$ Lidia A Dmitrieva, ${ }^{5}$ Konstantin G Gurevich
}

\begin{abstract}
About 341 (average age of $38.0 \pm 2.5$ years) patients with periodontal disease were included in this study. All the patients were not treated for periodontal disease for a period of 6 months prior to this study. All the patients were not on any hormonal therapy. Antibodies to Porphyromonas gingivalis ( $P$. gingivalis) were determined in blood serum by enzyme-linked immunosorbent assay (ELISA) method. Findings from this study suggest immune response to $P$. gingivalis is more effective in males than in females. Smoking and obesity tends to reduce effective immune response.
\end{abstract}

Keywords: Periodontal disease, Immune response, $P$. gingivalis.

How to cite this article: Tebloeva LM, Revazova ZE, Fabrikant KG, Dmitrieva LA, Gurevich KG. Differences in Immune Response to Porphyromonas gingivalis. J Contemp Dent Pract 2014;15(5):573-575.

\section{Source of support: Nil}

Conflict of interest: None

\section{INTRODUCTION}

Porphyromonas gingivalis is a Gram-negative obligate anaerobe found with high frequency in subgingival space of persons with periodontitis. $P$. gingivalis seems to be the main cause of periodontal bone loss and progression of periodontal disease. ${ }^{1,2}$ This bacterium is found in high frequency in persons with periodontitis where it participates in the initiation and establishment of chronic, infectious biofilms. These biofilms facilitate the long-term survival of $P$. gingivalis and induce an inflammatory reaction that is responsible for the destruction of the hard and soft tissue supporting structures of the teeth. In addition $P$. gingivalis can invade and persist in the cells of the gingival tissue. ${ }^{3}$

\footnotetext{
${ }^{1}$ Postdoctoral, ${ }^{2,3}$ Assistant Professor, ${ }^{4,5}$ Professor

1,2,4 Department of Periodontology, Moscow State University of Medicine and Dentistry, Moscow, Russia

${ }^{3,5}$ Department of Healthy Life for Sustainable Development (UNESCO), Moscow State University of Medicine and Dentistry, Moscow, Russia
}

Corresponding Author: Laura M Tebloeva, Postdoctoral Department of Periodontology, Moscow State University of Medicine and Dentistry, Moscow, Russia, Phone: +79163023962, e-mail: laurel178@mail.ru
It is hypothesized that the disease progression is due to a combination of several factors, including the presence of periodontopathic bacteria, high levels of proinflammatory cytokines, matrix metalloproteinases (MMPs), and prostaglandin $\mathrm{E}_{2}\left(\mathrm{PGE}_{2}\right)$, low levels of interleukin-10 (IL-10), transforming growth factor- $\beta$ (TGF- $\beta$ ), and tissue inhibitors of metalloproteinases (TIMPs). In this concept, it is clear that the balance of cytokines determines whether tissue destruction occurs or homeostasis is maintained. ${ }^{4}$ The role played by bacterial pathogens in determining the progression of the disease and periodontal breakdown is highly complex, and example being the disease is not associated with a single species, but rather a wide range of pathogenic bacteria. ${ }^{5}$

The first conclusive evidence that the host response played an important role in periodontal breakdown was demonstrated on beagles by using a potent cyclooxygenase inhibitor (flurbiprofen), which reduced the amount of bone loss caused by periodontal disease. ${ }^{6}$

\section{AIMS}

To study possible factors influencing on immune response to $P$. gingivalis.

\section{MATERIALS AND METHODS}

The sample in this study comprised 341 patients with periodontal disease. This study was approved by the Human Subject Review Board of the Moscow State University for Medicine and Dentistry. Only patients from 21 to 50 years of age were included, with the average age being $38.0 \pm$ 2.5 years. About $30.1 \%$ of patients were men. All women were had menstrual cycles (premenopause). All the patients had not been treated for periodontal disease 6 months prior to enrolment in this study. None of the patients were on hormonal therapy.

Patients were asked about history of disease, smoking, and physicals, such as weight and height measured. Body mass index (BMI) was calculated as weight $(\mathrm{kg}) /$ height $\left(\mathrm{m}^{2}\right)$. Patients with BMI $30 \mathrm{~kg} / \mathrm{m}^{2}$ were recognized as 'obese'.

Antibodies to $P$. gingivalis were measured in serum by ELISA method. Reactivates were tested using an ELISA described previously with some modifications. ${ }^{7}$ Unwashed whole cells of $P$. gingivalis were prepared from fresh 
bacterial culture by centrifuging at $3,400 \times$ gm for 15 minutes at $4^{\circ} \mathrm{C}$ without washing. For washed whole cells, bacteria were collected by centrifugation and resuspended in phosphate buffered saline (PBS) by pipetting. The centrifugation and washing steps were repeated. Both the unwashed and washed bacteria were collected and freeze-dried. The dried bacteria were weighed and used as antigen for whole-cell ELISA. ELISA plates were coated with $10 \mu \mathrm{g}$ of the freezedried bacteria resuspended in $100 \mu \mathrm{l}$ of ELISA coating buffer per well. After overnight blocking at $4^{\circ} \mathrm{C}$ with $1 \%$ skim milk in PBS with $0.5 \%$ Tween-20 (PBS-T), each serum sample was serially diluted with $1 \%$ skim milk in PBS-T, added to the wells and incubated for 1 hour at $37^{\circ} \mathrm{C}$. The wells were then incubated for 1 hour at $37^{\circ} \mathrm{C}$ with alkaline phosphatase-conjugated goat, antimouse IgG, IgA and IgM (Invitrogen, Carlsbad, CA, USA) at a dilution of 1:1,000. Subsequently, $P$. gingivalis-specific antibody was detected by chromogenic development using para-nitrophenyl phosphate as the alkaline phosphatase substrate. Absorbance at OD405 was measured at different time points; 15 and 30 minutes, 1 and 2 hours. The titer of each antiserum recognizing human lipopolysaccharide (LPS) and outer membrane vesicles (OMV) from $P$. gingivalis 33,277 was determined using the same ELISA protocol, except the microtiter wells were initially coated with antigen at $100 \mathrm{ng}$ per well. In the absorption assay, each serum sample was diluted at 1:1,000 in PBS and preincubated with $10 \mathrm{ng} / \mathrm{ml}$ of LPS or OMV purified from strain 33,277 for 1 hour at $37^{\circ} \mathrm{C}$. Then, the absorbed serum samples were passed through a Detoxigel ${ }^{\mathrm{TM}}$ (Thermo Fisher Scientific, Waltham, Massachusetts) column twice to remove possible contaminant LPS and LPS-associated molecules. An limulus amebocyte lysate (LAL) assay was performed to confirm that the serum did not contain any detectable LPS. The purified sera were used for ELISA.

The serum samples were stored at $-70^{\circ} \mathrm{C}$ before detection. IgG, IgM and IgA were measured.

Multiple analysis of variance (MANOVA) test was used for statistical investigations at $\alpha=0.05$.

\section{RESULTS}

We found influence of gender factor on activity of immune response. Men had higher levels of IgG and lower levels of $\operatorname{IgA}$ and $\operatorname{IgM}$ then women (Table 1). We also found that behavior risk factors influence activity of the immune system of patients with periodontal disease. Smoking increased levels of $\operatorname{IgA}$ and $\operatorname{IgM}$ and decreased those of IgG.

Influence of obesity and smoking to immune response was similar (Table 2). Obese patients showed lower levels of $\operatorname{IgG}$ and higher levels of $\operatorname{IgA}$ and $\operatorname{IgM}$ with reference to
$P$. gingivalis. Both obesity and smoking significantly influenced reduction in IgG levels, but only in females $(\mathrm{p}<0.05)$.

We demonstrated influence of clinical factors on immune response where patients with pocket depth from 5.0 to $5.9 \mathrm{~mm}$ had the higher level of IgG and the lower level of IgA and IgM (Table 3).

\section{DISCUSSION}

Periodontitis is a complex disease in which involves intricate interactions of the biofilm with the host immunoinflammatory response and subsequent alterations in bone and connective tissue homeostasis. ${ }^{2}$ The levels of Gram-negative bacteria in the subgingival plaque biofilm play an important role in progression of periodontal disease. ${ }^{3,5}$ Chronic periodontal infection results in inflammation, destruction of connective tissues, alveolar bone resorbtion and tooth loss. Inflammatory and immune response is triggered by periodontal bacteria, $P$. gingivalis. ${ }^{3}$

A range of host cells can be stimulated by $P$. gingivalis to produce proinflammatory cytokines that are implicated in periodontal disease pathogenesis. Classical periodontal disease characteristics include apical migration of the functional epithelium, gingival ulcerations, formation of periodontal pockets at the gingival sulcus, and alveolar bone resorption resulting in tooth mobility and tooth loss. ${ }^{3}$

It is known that high IgG levels correspond with effective immune response against $P$. gingivalis and good response to

Table 1: Sex and smoking differences in immunoglobulin levels

\begin{tabular}{lllll}
\hline Sex & Smoking & $\lg A(g / l)$ & $\lg M(g / l)$ & $\lg G(g / l)$ \\
\hline Male & Yes & $7.5 \pm 1.5$ & $6.6 \pm 1.4$ & $10.3 \pm 1.2$ \\
& No & $3.5 \pm 1.3^{\dagger}$ & $2.7 \pm 1.2^{\dagger}$ & $20.1 \pm 1.4^{\dagger}$ \\
Female & Yes & $5.7 \pm 1.4^{*}$ & $4.3 \pm 1.2^{*}$ & $8.4 \pm 1.3$ \\
& No & $3.8 \pm 1.2^{\dagger}$ & $3.3 \pm 1.5^{\dagger}$ & $16.2 \pm 1.5^{\star \dagger}$ \\
\hline
\end{tabular}

${ }^{*} p<0.05$ difference in men; ${ }^{\dagger} p<0.05$ difference in smokers

Table 2: Sex and obesity differences in immunoglobulin levels

\begin{tabular}{lllll}
\hline Sex & Obesity & $\lg A(g / l)$ & $\operatorname{lgM}(g / l)$ & $\operatorname{lgG}(g / l)$ \\
\hline Male & Yes & $7.8 \pm 1.3$ & $7.6 \pm 2.4$ & $12.8 \pm 1.9$ \\
& No & $3.2 \pm 1.3^{\dagger}$ & $1.3 \pm 1.3^{\dagger}$ & $17.3 \pm 1.1^{\dagger}$ \\
Female & Yes & $5.4 \pm 1.8^{*}$ & $5.3 \pm 1.4^{*}$ & $9.2 \pm 1.2^{*}$ \\
& No & $4.2 \pm 1.2^{\dagger}$ & $4.4 \pm 1.2^{\dagger *}$ & $15.2 \pm 2.4^{\dagger}$ \\
\hline
\end{tabular}

${ }^{*} p<0.05$ difference from men; ${ }^{\dagger} p<0.05$ difference from persons with obesity

Table 3: Differences in immunoglobulin levels due to pocket depth

\begin{tabular}{llll}
\hline $\begin{array}{l}\text { Pocket depth } \\
(\mathrm{mm})\end{array}$ & $\operatorname{lgA}(\mathrm{g} / \mathrm{l})$ & $\operatorname{lgM}(\mathrm{g} / \mathrm{l})$ & $\lg \mathrm{g}(\mathrm{g} / \mathrm{l})$ \\
\hline $4.0-4.9$ & $7.8 \pm 1.4^{\dagger}$ & $4.6 \pm 1.3^{\dagger}$ & $11.3 \pm 1.3^{\dagger}$ \\
$5.0-5.9$ & $3.4 \pm 1.3^{*}$ & $2.4 \pm 1.2^{*}$ & $19.1 \pm 1.2^{*}$ \\
$6.0-6.9$ & $5.6 \pm 1.5^{\star \dagger}$ & $6.8 \pm 1.2^{* \dagger}$ & $9.1 \pm 1.2^{\dagger}$ \\
\hline
\end{tabular}

${ }^{*} \mathrm{p}<0.05$ difference from group with pocket depth 4.0 to $4.9 \mathrm{~mm}$; ${ }^{\dagger} p<0.05$ difference from group with pocket depth 5.0 to $5.9 \mathrm{~mm}$ 
treatment of periodontal disease. Immunoglobulin $\mathrm{G}(\mathrm{IgG})$ class, but not IgA or IgM, antibodies to peptides of the Porphyromonas gingivalis chaperone $\mathrm{HtpG}$ predict health in subjects with periodontitis by a fluorescence ELISA. ${ }^{3,4}$

\section{CONCLUSION}

Findings in this study demonstrate possible factors influencing to immune response to $P$. gingivalis. Our findings suggest that women have worse immune response than men, both smoking and obesity results in depression of IgG levels to P. gingivalis. Patients with pocket depth 4 to $4.9 \mathrm{~mm}$ have the best immune response.

\section{CLINICAL SIGNIFICANCE}

Results from our study provides information that is clinically useful for periodontologists and general dentists in understanding the possible variables that are associated with periodontal bone loss and also provides the immunological basis for response to $P$. gingivalis.

\section{REFERENCES}

1. Socransky SS, Haffajee AD. The nature of periodontal diseases. Ann Periodontol 1997 Mar;2(1):3-10.

2. Socransky SS, Haffajee AD, Cugini MA, Smith C, Kent RL Jr. Microbial complexes in subgingival plaque. J Clin Periodontol 1998 Feb;25(2):134-144.

3. Progulske-Fox A, Kozarov E, Dorn B, Dunn W Jr, Burks J. Porphyromonas gingivalis virulence factors and invasion of cells of the cardiovascular system. J Periodontal Res 1999 Oct;34(7): 393-399.

4. Gemmell E, Yamazaki K, Seymour GJ. Destructive periodontitis lesions are determined by the nature of the lymphocytic response. Crit Rev Oral Biol Med 2002;13(1):17-34.

5. Wang J, Qi J, Zhao H, He S, Zhang Y, Wei S, Zhao F. Metagenomic sequencing reveals microbiota and its functional potential associated with periodontal disease. Sci Rep 2013;3:1843.

6. Williams RC, Jeffcoat MK, Kaplan ML, Goldhaber P, Johnson HG, Wechter WJ. Flurbiprofen: a potent inhibitor of alveolar bone resorption in beagles. Science 1985 Feb 8;227(4687):640-642.

7. Tsuha Y, Hanada N, Asano T, Abei T, Yamaguchi S, Salam MA, Nakan R, Takeuchi H, Kurosaki N, Senpuku H. Role of peptide antigen for induction of inhibitory antibodies to Streptococcus mutans in human oral cavity. Clin Exp Immun 2004 Aug; 137(2):393-401. 